DOI: 10.17117/na.2016.10.03.099

Поступила (Received): 02.10.2016 http://ucom.ru/doc/na.2016.10.03.099.pdf

\title{
Горохова М.В.
}

\author{
Оценка влияния технологии изготовления \\ прямошовных и спиральношовных труб на уровень \\ концентрации напряжений в сварном шве
}

\author{
Gorokhova M.V. \\ Assessment of influence of manufacturing techniques \\ straight-line-seam and spiralno sutural pipes on the \\ level of concentration of tension in a welded seam
}

Рассмотрено, как влияет технология изготовления сварных труб на уровень концентрации напряжений в сварном шве при их статическом нагружении. Выполнен анализ влияния формы усиления сварного шва, смещения кромок и овальности труб на коэффищиент концентрации напряжений

Ключевые слова: концентрация напряжений, сварной шов трубы

Горохова Марина Венидиктовна

Кандидат технических наук, доцент

Волжский государственный университет водного транспорта

2. Нижний Новгород, ул. Нестерова, 5

\begin{abstract}
It is considered how the manufacturing techniques of welded pipes influence the level of concentration of tension in a welded seam at their static loading. The analysis of influence of a form of strengthening of a welded seam, shift of edges and ovality of pipes on coefficient of concentration of tension is made
\end{abstract}

Key words: concentration of tension, welded seam of a pipe

Gorokhova Marina Venidiktovna
Candidate of Engineering Sciences, Associate
Professor
Volga state university of water transport
Nizhni Novgorod, Nesterova st., 5

На трассах магистральных трубопроводов в настоящее время уложены как прямошовные, так и спиральношовные трубы. Хотя спиральношовных труб в общей длине нефтепроводов значительно меньше, но в одинаковых условиях эксплуатации они показывают меньшую дефектность, чем прямошовные трубы, что подтверждают объективные данные внутритрубной диагностики. При этом уровень дефектности, связанный с условиями строительства и эксплуатации трубопровода, для прямошовных и спиральношовных труб практически одинаков. В тоже время количество металлургических дефектов, («раскатанные загрязнения») в спиральношовных трубах значительно меньше. Это, очевидно, связано с условиями проката листа (ширина листа меньше, чем для изготовления прямошовных труб, и не зависит от диаметра изготовляемых труб) и термообработкой труб, в ходе которой отбраковываются трубы, имеющие значительные включения. В этом плане интересным будет проведение сравнительного исследования статической прочности прямошовных и спральношовных труб. 
Большое влияние на статическую прочность труб оказывает концентрация напряжений в сварном стыке. Технические условия производство сварных труб предполагают равнопрочность сварного шва и основного металла трубы. Поэтому предполагается равновероятное разрушение трубы по сварному шву и основному металлу при статическом испытании труб внутренним давлением.

Практика испытаний сварных труб показывает, что действительно, при однократном нагружении разрушение труб происходит как по сварным швам, так и по основному металлу. При этом разрушение спиральношовных труб по сварным швам практически отсутствует, а по продольным швам случаи разрушения составляют около 40\%. Разрушение трубы, содержащей зону конструктивной концентрации напряжений (сварной шов), происходит либо за счет исчерпания пластичности в зоне концентрации напряжений, либо в мембранной зоне с образованием утончения в месте разрыва.

Рассмотрим, как влияет технология изготовления сварных труб на уровень концентрации напряжений в сварном шве.

Одним из основных факторов, влияющим на величину концентрации напряжений в сварном шве, является форма усиления сварного шва. Данный вопрос подробно рассмотрен в работе [1], в которой приведена следующая формула для расчета коэффициента концентрации напряжений в сварном шве:

$$
\alpha_{\sigma}=1+\frac{2}{\pi \cdot A} \cdot\left[R \cdot \ln \frac{b+r}{r}-R_{0}+r_{1} \cdot R_{1}-r_{1}^{2} \cdot R_{2}+T\right]
$$

где A, R, R0, R1, R2, T - коэффициенты, зависящие от соотношения размеров сварного стыкового соединения, вычисляются по формулам:

$$
\begin{gathered}
A=\frac{a_{1} \cdot\left(\operatorname{ch} a_{1}\right)}{k}+\frac{a_{1}^{2}}{2} \cdot r_{1} \cdot \operatorname{sh} a_{1} ; \quad R=a_{1}+0,167 \cdot a_{1}^{3}+0,008 \cdot a_{1}^{5} ; \\
R_{0}=a_{1}+0,303 \cdot a_{1}^{3}+0,019 \cdot a_{1}^{5} ; \quad R_{1}=a_{1}+0,33 \cdot a_{1}^{3}+0,033 \cdot a_{1}^{5} ; \\
R_{2}=a_{1}+0,167 \cdot a_{1}^{3}+0,038 \cdot a_{1}^{5} ; \quad T=\operatorname{sh} a_{1} \\
a_{1}=a \cdot b ; r_{1}=\frac{r}{b} ; a=\sqrt{\frac{k \cdot(\delta+2 \cdot c)}{c \cdot b \cdot \delta} ; k=0,9 \cdot\left[\frac{\delta}{(\delta+c)}\right]^{2},}
\end{gathered}
$$

b - толщина стенки трубы; $\delta$ - ширина сварного шва; с - высота выступа сварного шва; $r$ - радиус перехода от наплавленного к основному металлу.

Наиболее существенное влияние на коэффициент концентрации напряжений $\alpha_{\sigma}$ оказывают радиус перехода наплавленного металла к основному, высота и ширина выступа сварного шва. Для реальных магистральных трубопроводов радиус сопряжения основного металла с наплавленным равен 0,25 - 0,5 мм, а среднее значение высоты выступа сварного шва и его ширины составляют соответственно 3 и 20 мм. При этом значение $\alpha_{\sigma}$ для продольного шва сварных труб оказывается равным 1,58 - 1,65 (для внутреннего шва) и 1,3 - 1,5 (для наружного шва). Все эти теоретические значения коэффициента концентрации напряжений сопоставимы с экспериментальными значениями данного коэффициента , которые для сиральношовных труб находятся в пределах 1,6. А так как процесс автоматической сварки, который используется на трубопрокатных заводах, обеспечивает большую стабильность геометрических параметров 
усиления сварного шва, то и значения коэффициента концентрации напряжений, которые обусловлены формой шва, так же будут стабильными.

Рассмотрим местное повышение напряжений, вызываемое изгибными эффектами в зоне сварного шва. В общем случае изгибные напряжения равны

$$
\sigma_{\text {из }}=\sigma_{\text {см }}+\sigma_{\text {уг }}+\sigma_{\text {ов }}
$$

где $\sigma_{\text {см }}$ - изгибные напряжения от смещения кромок; $\sigma_{\text {уг }}-$ изгибные напряжения от угловатости сварного соединения; $\sigma_{\text {ов }}-$ изгибные напряжения от овальности сечения трубы.

Величину изгибных напряжений в случае смещения кромок можно вычислить по формуле:

$$
\sigma_{\mathrm{cM}}= \pm \frac{3 \cdot \Delta}{1+\left(\frac{b \cdot k}{2}\right)} \cdot \sigma_{\mathrm{H}}, \quad k=\sqrt{\frac{6 \cdot P \cdot D_{\mathrm{BH}}}{E \cdot \sigma^{3}}}
$$

где $\sigma_{\text {н }}$ - номинальное напряжение (безмоментная зона), $\Delta=\frac{h}{\delta}$ - относительное смещение, $\mathrm{h}$ - величина смещения кромок, $D_{\text {вн }}$ - внутренний диаметр трубы, $E$ - модуль упругости материала трубы.

Для расчета изгибных напряжений из-за угловатости в районе продольного шва трубы можно использовать эмпирическую формулу, которая показывает наилучшую сходимость с экспериментальными данными:

$$
\sigma_{\text {уг }}= \pm \frac{6 \cdot b}{\delta} \cdot \operatorname{tg} \beta \cdot \sigma_{\mathrm{H}}
$$

где $\beta$ - угол между осью стенки трубы и осью сварного шва.

Влияние начальной овальности сечения на напряженное состояние труб можно оценить с помощью формулы, полученной с учетом изменения овальности от действия внутреннего давления Р:

$$
\sigma_{\mathrm{oв}}=\frac{3 \cdot U \cdot \sigma_{\mathrm{H}}}{\left(\frac{\delta}{R}\right) \cdot\left[1+4 \cdot(1-\mu)^{2} \cdot\left(\frac{P}{E}\right) \cdot\left(\frac{R}{\delta}\right)^{3}\right]}, \quad U=\frac{\left(D_{\max }-D_{\min }\right)}{2 \cdot R}
$$

где R - номинальный радиус трубы, $\mathrm{U}$ - овальность трубы.

Для рабочих давлений и начальной овальности допускаемой СНИП для магистральных нефтепроводов и равной 1\%, для трубы диаметром 720 мм и толщиной стенки $11 \mathrm{мм} \sigma_{\text {ов }}=0,15 \sigma_{\mathrm{H}}$.

Местное повышение напряжений от изгибных эффектов, вызванных смещением кромок, угловатостью сварного соединения и овализацией сечения, приходится на зону концентрации напряжений сварного шва. При этом $\alpha_{0}$ при растяжении и изгибе оказывается практически одинаковыми. Принимая это во внимание, максимальные напряжения в зоне сварного шва можно вычислить по формуле:

$$
\sigma_{\max }=\alpha_{\sigma} \cdot\left(\sigma_{\mathrm{н}}+\sigma_{\text {из }}\right) \text {. }
$$

Проверка достоверности соотношения (1) для расчета суммарного эффекта местного повышения напряжений в сварных соединениях была проведена с использованием экспериментальных данных работы [2]. Результаты этой проверки приведены в табл.1. В табл.1 и в дальнейшем для характеристики местного возмущения напряженного (деформированного) состояния в зоне сварного соединения трубы со смещением кромок, угловатостью и овализацией 
использовалось отношение в максимально напряженной зоне сварного шва к соответствующим величинам в безмоментной зоне (номинальные напряжения и деформации), условно обозначаемое как коэффициент концентрации:

$$
\alpha^{*}=\frac{\sigma_{\max }}{\sigma_{\mathrm{H}}}=\left(1 \pm \frac{3 \cdot \Delta}{1+\frac{b \cdot k}{2}} \pm \frac{6 \cdot b}{\delta} \cdot \operatorname{tg} \beta \pm \frac{3 \cdot U}{\frac{\delta}{R} \cdot\left[1+4 \cdot\left(1-\mu^{2}\right) \cdot\left(\frac{P}{E}\right) \cdot\left(\frac{R}{\delta}\right)^{3}\right]}\right)
$$

\section{таблица 1}

\begin{tabular}{|l|c|c|c|c|c|c|c|c|c|c|}
\hline $\begin{array}{c}\text { № } \\
\text { трубы }\end{array}$ & \multicolumn{5}{|c|}{ Параметры сварного шва } & \multicolumn{4}{c|}{$\begin{array}{c}\text { Коэффициент } \\
\text { концентрации }\end{array}$} \\
\cline { 2 - 12 } & $\begin{array}{c}b, \\
\text { мM }\end{array}$ & $\begin{array}{c}r, \\
\text { мм }\end{array}$ & $\begin{array}{c}\delta, \\
\text { мм }\end{array}$ & $\begin{array}{c}c, \\
\text { мм }\end{array}$ & $\begin{array}{c}h, \\
\text { мм }\end{array}$ & $\begin{array}{c}\beta, \\
\text { град }\end{array}$ & $\alpha_{\sigma}$ & $\frac{\sigma_{\text {из }}}{\sigma_{\mathrm{H}}}$ & $\alpha_{p}^{*}$ & $\alpha_{\ni}^{*}$ \\
\hline I & 23 & 0,25 & 11 & 4,4 & 4,0 & 11,5 & 1,75 & 3,74 & 8,29 & 8,0 \\
\hline II & 28 & 0,25 & 11 & 3,6 & 0,5 & 7 & 1,48 & 2,11 & 4,60 & 4,7 \\
\hline III & 34 & 0,25 & 11 & 1,0 & 3,2 & 4,5 & 1,22 & 2,26 & 4,06 & 4,1 \\
\hline IV & 25 & 0,25 & 9 & 1,2 & 1,2 & 0 & 1,29 & 0,40 & 1,81 & 2,0 \\
\hline
\end{tabular}

В табл.1 приняты следующие обозначения: $\sigma_{p}^{*}$ - расчетный коэффициент концентрации напряжений; $\sigma_{\ni}^{*}$ - коэффициент концентрации напряжений, полученный поляризационно-оптическим методом в эксперименте [2] на моделях сварного соединения из оптически чувствительного материала.

Из табл.1 видно, что расхождение между экспериментальными и расчетными значениями коэффициентов концентрации не превосходят 10\%.

Расчет значений $\alpha_{\text {max }}$ проводится по формуле (2) с введением максимальных значений смещений кромок и угловатости и среднего значения ширины валика, равного примерно двум толщинам стенки.

На уровень концентрации напряжений в сварном шве трубы влияют так же и условия формирования сварных швов труб. Если не учитывать мелкие подробности формирования труб при их изготовлении, то можно принять примерно равные условия формирования сварного шва в прямошовных трубах до экспандирования и спиральношовных трубах.

Таким образом форма усиления шва, смещения кромок и овальность труб при различных технологиях их изготовления различаются незначительно. Именно эти параметры нормируются в ТУ на изготовление труб. Подстановка предельно допустимых параметров сварного соединения ( $\alpha_{\phi}=1,6 ; \Delta=$ $30 \%$; $U=1 \%$ ) в формулу (2) показывает, что уровень концентрации напряжений в сварном шве не должен превышать значения $\alpha=3$. Это обеспечивает равнопрочность сварного шва основному металлу в не зависимости от его ориентации.

Вместе с тем, даже незначительные превышения требований ТУ на форму шва могут привести к инициированию разрушения по продольному сварному шву.

На стадии изготовления труб ( окончательное формирование спиральношовных труб и формирование прямошовных труб до экспандирования) угловатость сварного шва незначительна и ее можно не учитывать при расчете. 
Угловатость шва сварных труб окончательно формируется при правке труб в экспандере. Так, если предусмотрено гидравлическое экспандирование, то наружный валик шва упирается в экспандер и формируется «отрицательная» угловатость. Если правка труб осуществляется механическим экспандером, то в него упирается внутренний валик шва и угловатость формируется в виде «домика». Таким образом, нормирование угловатости в сварном шве можно проводить соответствующим нормированием формы усиления шва. При этом определение максимальной угловатости сварного шва проводится из условия взаимодействия валика сварного шва трубы с внутренним или внешним экспанлдером по полуэмпирической формуле:

$$
\operatorname{tg} \beta=2 \cdot\left(\frac{\sqrt{D^{2}-[D-(\delta+c)]^{2}}}{D-(\delta+c)}\right),
$$

где D - диаметр трубы, $\delta$ - толщина стенки трубы; с - высота усиления сварного шва.

Для средних диаметров трубы (700-1000 мм) и толщин стенок (10мм) подстановка максимально допустимого значения высоты усиления сварного шва (Змм) получаем $\operatorname{tg} \beta=0,3 . . .0,4$, что приводит к увеличению максимальных коэффициентов концентрации до $\alpha=5$... 7. А это уже соответствует возможности реализации разрушений труб по сварному шву при статитческих испытаниях внутренним давлением.

Известно так же, что уровень максимальных напряжений в стыковом сварном шве зависит не только от концентрации напряжений, но и от ориентации шва относительно главных напряжений в трубе. С учетом этого при нагружении трубы внутренним давлением в наиболее неблагоприятных условиях находится продольный шов, а при возникновении продольных усилий в турбопроводе и изгиба - спиральный шов. Соответственно, ограничения на отклонения в геометрии сварного стыкового соединения должны быть различными для продольного и спирального швов.

Одним из различий в технологии изготовления прямошовных и спиральношовных сварных труб является процедура окончательного формирования прямошовных труб в экспандере.

В процессе правки трубы в экспандере происходит увеличение ее диаметра с общим удлинением периметра до 1\% от номинального. Учитывая, что после статических испытаний труб до разрушения периметр увеличивается примерно на 5 - 10\%, следует рассмотреть вопрос о снижении остаточного ресурса трубы из-за экспандирования.

Общий уровень нагружения труб при правке в экспандере таков, что металл стенки трубы находится в пластическом состоянии по всему периметру трубы, в том числе и в мембранной зоне. При этом, для пластичных трубных сталей, изменнение механических характеристик (снижение предельной пластичности, увеличение предела текучести) в мембранной зоне незначительно и не сказывается на прочностном ресурсе трубы. В то же время в зонах концентрации (зона сварного соединения) возможно перераспределение напряжений и деформаций со значительным исчерпанием пластичности материала. 
Проведем оценку возможности изменения остаточного прочностного ресурса трубы в процессе экспандирования. Известно, уровень пластических деформаций в зоне концентрации напряжений можно оценить по формуле:

$$
e_{\max }=\alpha^{2} \cdot e_{n}
$$

где $\alpha$ - теоретический коэффициент концентрации напряжений в сварном шве.

В первом приближении можно не учитывать процесс формоизменения в зоне шва при экспандировании, поэтому в качестве концентратора можно рассматривать только форму усиления шва и смещение кромок. Таким образом, в расчете можно принять максимальное значение коэффициента концентрации напряжений, равное 3.

Принимая $e_{n}=0,01$, получаем, что уровень пластической деформации в зоне сварного шва не превышает 9\%. В то же время предельная пластичность материала $\left(e_{f}=\ln \frac{1}{1-\psi_{f}}\right)$ для трубных сталей составляет менее $60 \%$... 70\%. Таким образом, уровень исчерпания пластичности в зоне сварного шва хотя и незначителен, но может привести к снижению усталостной долговечности сварного соединения при эксплуатации. Что касается рассматриваемой в данной статье статической прочности труб, то, поскольку уровень пластических деформаций при экспандировании далек от критического и не приводит к уменьшению временного сопротивления $\sigma_{\text {в }}$ и истинного сопротивления разрыву $S_{k}$, процедура экспандирования не сказывается на уровне статической прочности труб.

Таким образом, рассматривая влияния технологии изготовления прямошовных и спиральношовных труб на уровень концентрации напряженений, установлено, что в процессе правки прямошовных труб в экспандере происходит формирование допполнительного дефекта формы шва - угловатости («домика»), что приводит к увеличению уровня коцентрации напряжений в сварном шве и снижению прочностного и усталостного ресурса трубы. Однако, уровень исчерпания пластичности материала в зоне сварного шва при экспандировании недостаточен для снижения статической прочности труб, но может сказаться на усталостном ресурсе трубы.

\section{Список используемых источников:}

1. Навроцкий Д.И. Прочность сварных соединений с учетом концентрации напряжений. М.: Машиностроение, 1968. 170 с.

2. Гусенков А.П., Аистов А.С. Исследование малоцикловой прочности труб большого диаметра магистральных газо- и нефтепроводов // Машиноведение, 1975. №3 С.61-71.

(C) 2016, Горохова М.в.

Оценка влияния технологии изготовления прямошовных и спиральношовных труб на уровень концентрации напряжений в сварном шве
(C) 2016, Gorokhova M.V.

Assessment of influence of manufacturing techniques straight-line-seam and spiralno sutural pipes on the level of concentration of tension in a welded seam 